\title{
Editorial: The Use of Simulation in Advancing Clinical Social Work Education and Practice
}

\author{
Kenta Asakura ${ }^{1} \cdot$ Marion Bogo ${ }^{2}$ \\ Accepted: 7 April 2021 / Published online: 8 May 2021 \\ (c) The Author(s), under exclusive licence to Springer Science+Business Media, LLC, part of Springer Nature 2021
}

Society's commitment to the well-being of its members is demonstrated through the quality of its health and social services. These in turn are highly dependent on the effectiveness of the interdisciplinary practitioners who deliver these services. As a result, professional schools bear the responsibility of preparing graduates for "accomplished and responsible practice in the service of others... [students] must come to understand in order to act, and [students] must act in order to serve" (Shulman, 2005, p. 53). Professional education and training of clinical social workers therefore play an essential role in ensuring the delivery of high-quality services. Over half of all social workers in the U.S. and Canada (53\%) engage in clinical practice across a range of settings-from hospitals, child welfare agencies, mental health and addiction programs, schools, to private practice (Association of Social Work Boards, 2017). As we write this editorial in the midst of COVID-19 pandemic, this responsibility of professional education in ensuring the quality of health and social services and ethical, responsible and competent care provided by clinical social workers is most acutely felt.

From fear of contracting the virus, heightened uncertainty over employment and finance, social isolation from physical distancing measures, to immense parenting stress over school closure and childcare, COVID has brought on widespread emotional distress and is expected to leave long-lasting mental health impacts among many individuals (Galea et al., 2020; Pfefferbaum \& North, 2020). What COVID also exposed is the societal inequalities and disparities, in that not everyone is impacted equally by this public health and economic crisis. With a number of vulnerability factors prior to COVID- from poverty (e.g., precarious housing and

Kenta Asakura

kenta.asakura@carleton.ca

1 Carleton University School of Social Work, Ottawa, ON, Canada

2 Factor-Inwentash Faculty of Social Work, University of Toronto, Toronto, ON, Canada employment, food insecurity), barriers to healthcare access (e.g., insurance) and accurate health information (e.g., language barrier, digital literacy), to overrepresentation in the essential work sectors (e.g., grocery stores, frontline healthcare, public transportation), historically marginalized communities, especially Black, Indigenous and People of Color, have carried significantly disproportional burdens of COVID infection and mortality, highlighting the serious realities of racial and other inequalities in the U.S. (Hardy \& Logan, 2020; Parolin, 2021; Tai et al., 2021). COVID also contributed to a spike in the incidents of anti-Asian racism, xenophobia and related hate crimes in many communities (Haynes, 2021).

These structural issues also point to clinical social workers' important roles and responsibilities in this vulnerable time. Clinical social workers have served as the backbone of the health and social service systems during COVID, working with highly vulnerable and marginalized client populations (e.g., long-term care facilities, homeless shelters, child protection, emergency rooms, domestic violence shelters) as essential workers (Abrams \& Dettlaff, 2020). Even prior to COVID, clinical social workers have long been called on to provide quality services for society's vulnerable and marginalized. In taking on a biopsychosocial perspective as a theoretical lens (Berzoff, 2011) and commitment to social justice as a core value principle (National Association of Social Workers, 2017), clinical social workers are well positioned to conceptualize the linkage between structural injustices and one's health and wellbeing, and implement effective interventions (Asakura \& Maurer, 2018). The mission of social work education has always been to train the next generation of social workers. In the time of COVID, however, schools of social work are now more than ever called on to prepare clinical social workers to demonstrate competencies and provide services designed to address complex clinical issues among marginalized clients. As COVID affected the nature of in-class learning and field practicum experiences, simulation-based learning was able to provide a 
robust enhancement for learning to practice. Even before this current crisis, we conceived this Special Issue on simulation to advance our professional commitment to clinical social work education and practice.

\section{Historical Contexts of Clinical Social Work Education}

Historically, curriculum in schools of social work addressed this mission through offering academic courses to develop knowledge and understanding about practice and relegated teaching to $d o$ practice to the field practicum. Increasingly, in the mid-70s into the 80s, schools introduced skills laboratories to teach students basic communication and interviewing skills and studies on these innovations demonstrated their effectiveness (Clubok, 1978; Larsen \& Hepworth, 1982; Schinke et al., 1980). In part, the introduction of preparatory instruction for practice was a response to field instructors' advocacy. Field instructors noted that field learning involved learning a myriad of complex issues and dynamics beyond "the basics". With increased workload pressures, field instructors had less time for instruction and expected schools to provide the necessary foundational competencies, such as the ability to interview in a professional manner. While systematic data is not available, it appears that many programs developed interviewing courses or labs, especially in the undergraduate social work curriculum. Labs were fairly informal; students engaged in considerable peer-topeer role plays, some of which were video recorded and used for feedback and discussion. The pedagogical insight that emerged from these innovations was that students could be taught basic interviewing skills through practice with colleagues, followed by receiving feedback.

Spurred on by the movement in family therapy for direct observation and supervision of students, some social work schools installed one-way mirrors, as did many agencies. One-way mirrors provided direct observation of actual practice with focused, immediate corrective interventions (Minuchin \& Fishman, 1981; Montalvo, 1973). Following the interview, the student would receive feedback, although often the focus was on case conceptualization and planning future interventions. There is no literature on this approach to teaching practice in schools of social work, although some recent reflective pieces promote the use of direct observation of practice in the field practicum (Beddoe et al., 2011; Saltzburg et al., 2010).

\section{Emergence of Simulation-Based Clinical Social Work Education}

Presently, social work educators have seen the expansion of using simulation-based learning with trained actors. The distinguishing features of this approach are that simulations are systematically designed, usually based on the articulation of a set of competencies to be learned (Bogo et al., 2014). Since scenarios aim for authenticity, usually they are developed with social work practice experts in the field. Actors are trained in a way that represents the complexity of client situations and the nuanced nature of practice. While simulations are used in lab courses, studies in reviews of simulation found they are integrated into the curriculum of specific courses, providing teaching that links theory and practice (Kourgiantakis et al., 2020).

Anecdotally it seems that social work educators were using simulation with trained human actors as standardized clients, including drama students, as early as the 1980s (Berliner, 1982). Studies on this approach were few with increasing numbers emerging in the 2000s (Koprowska, 2003; Mole et al., 2006; Petracchi, 1999; Petracchi \& Collins, 2006; Robins et al., 2008). In a critical appraisal of the literature on the use of standardized client simulations (Logie et al., 2013) found 18 published studies. Only 7 years later a scoping review of the use of simulation in social work found 52 studies (Kourgiantakis et al., 2020). Of interest was the finding that about a third of the studies were in interprofessional practice, suggesting that social work educators were joining with allied health professionals who have been using simulation in teaching for decades. The scoping review found studies of simulation-based learning in both generalist and specialized areas of practice, as well as use of simulation to assess students' performance through the Objective Structured Clinical Examination (Bogo et al., 2011).

Studies and educational practice wisdom have demonstrated that simulation-based learning is an effective approach to develop competence in students with no harm to clients. Being actively involved in simulation followed by focused debriefing is consistent with numerous educational concepts (Bogo et al., 2014; Kourgiantakis et al., 2019, 2020). Active and experiential learning theory (Kolb, 1984; Schenck \& Cruickshank, 2015), observing others and being observed with immediate focused feedback consistent with social learning theory (Bandura, 1986) and deliberate practice (Rousmaniere, 2017), and insights from neuroscience research (Sousa, 2017; Taylor \& Lamoreaux, 2008) inform this powerful pedagogy. Furthermore, through reviewing their practice, preferably on video recordings, students experience the value of reflective practice and instructors can deliberately link a range of relevant concepts in their teaching (Schon, 1987). As social learning theory proposes 
(Bandura, 1986), vicarious learning has also been found to occur with a few studies demonstrating that health professions' students can learn from observing others conducting an interview. Indeed, two studies found higher scores in medical students' knowledge (Stegmann et al., 2012) and nursing students' performance after observing peers (Livsey \& Lavender-Stott, 2015). Similarly, a recent study in simulation-based social work education (Asakura et al., 2020a) suggested that the overall learning reported by observers was quantitatively comparable to interviewers. The qualitative part of the same study, however, found several unique learning processes associated with observational learning. Notably, all of these studies on simulation-based education agree that observational learning can be enhanced with an observation guide or rating scale, focusing students' attention on desired competencies.

\section{Introduction to the Special Issue}

As we look into the future of the use of simulation in clinical social work as an educational and professional discipline, there are a number of exciting new developments. As the first of its kind in a social work journal, we designed this Special Issue to canvas the most cutting-edge collection of scholarly work on the use of simulation in advancing clinical social work education and practice. We have brought together a total of 15 articles, which collectively inform how simulation can advance the field of clinical social work. This Special Issue consists of three aspects of this topic: (1) simulation-based teaching, learning and student assessment, (2) innovation using virtual simulation, and (3) simulation as a research methodology.

The first group of this Special Issue, consisting of 6 articles, focuses on simulation-based teaching, learning and student assessment. This group of articles provides social work educators with various theoretically and/or empirically informed pedagogies using simulation. In the first paper, Bogo and colleagues outline a highly developed, researchinformed program of simulation-based teaching, learning and student assessment at the University of Toronto. As a pioneer in introducing simulation to social work education and building empirical evidence of this type of pedagogy, the Toronto Simulation Model ("Toronto Model") urges social work educators to articulate practice competencies to guide the design and use of simulation in both generalist and specialized clinical practice courses. While much of simulation-based education was previously taking place in an in-person classroom, social work educators suddenly faced the challenge of remote, online teaching in Spring 2020. In fact, much of field education has also moved to a remote, online format (Mitchell et al., 2021). Bay and colleagues from Australia share their teaching firsthand experience from the past pandemic year and argue that it is possible to develop rigorous and accessible online clinical teaching. Building on the Toronto Model focused on in-person simulations, these authors provide concrete guidelines on how to deliver simulation-based teaching in an online, remote learning environment. The next paper also focuses on online, remote teaching, introducing a teaching practice for Screening, Brief Intervention \& Referral to Treatment (SBIRT), an evidence-based early intervention program often used among clinical social workers. Faced with the early wave of COVID in 2020, Washburn and colleagues turned their inclass teaching into an online format and creatively used the opportunity to teach students about telehealth, using peer-topeer simulations. While telehealth has become a 'new norm' among healthcare professionals during COVID, appropriate education and training is essential for the success of this service delivery model in the long run. Both of these articles support this urgent need for training clinicians who can competently provide social work services via telehealth. Next, Pecukonis offers an innovative pedagogy that incorporates live supervision in a simulation-based teaching of Motivational Interviewing. In this article, the author provides a fivestep guideline on how to effectively integrate live supervision in further strengthening simulation-based learning in a clinical practice course. In the next two articles, readers will learn how simulation can be effectively utilized in training clinical social workers in two settings that have been heavily impacted by COVID: healthcare and public child welfare. Sollars and Xenakis, healthcare social workers in New York City, share their practice of developing a simulation-based continuing education program for clinical social workers in a healthcare setting. Furthermore, Rawlings and colleagues report results of a mixed-method study about an innovative simulation-based learning program designed to train Title IV-E students across three universities in California. These articles exemplify how readers, especially social work educators and trainers, might examine training gaps in their own practice settings and develop and evaluate innovative clinical training using simulation.

The second group of articles introduce four articles about an innovative use of virtual simulation in clinical social work. Lack of financial resources is often a barrier for many programs that aim to introduce enhanced methods for teaching practice. Innovative use of technology provides a novel pedagogy, and social work educators have already made use of virtual programs. One popular example, used in other professions, is the use of virtual reality, such as Second Life, in interactive computer-generated experiences in a simulated environment (Reinsmith-Jones, et al., 2015). Educating for assessment in screening and brief intervention skills for clients with substance use is described and studied by Putney and colleagues (2019). Online interactive client simulation technology had already been used in social work education 
prior to the pandemic (Asakura et al., 2020a, b; Washburn $\&$ Zhou, 2018). The first paper in this group of the Special Issue was contributed by Smith and colleagues, who discuss an online clinical training program that uses virtual clients (i.e., trained actors who portray a well-designed client scenario in an online format). Presenting alcohol use/misuse, these virtual clients provide students with opportunities to learn and practice Cognitive Behavioral Therapy and Motivational Interviewing in an online platform. In this mixed methods study, the authors report good feasibility, acceptability, and effectiveness of this program and argue for a promising pedagogical opportunity of using virtual simulations in remote learning. The next three articles focus on a ground-breaking use of virtual reality (VR) in clinical education and practice. McDonald and colleagues share an innovative development of a VR training program for social workers in child welfare. Using the theory of deliberate practice and cognitive load theory, the authors conceptually argue that it is important for educators to use theories of teaching and learning in developing an effective simulation-based educational program using VR technologies. Lanzieri and colleagues describe and evaluate an original VR platform that allows students to experience the physical and social environments of New York City's Lower East Side. Positive learning benefits reported in this pilot study shows how VR can offer a promising pedagogical technology that can assist clinical social work students in experientially learning the important linkage between the micro and macro levels of human development. Finally, Trahan and colleagues report a unique use of VR in developing and implementing a clinical treatment program. These authors discuss mobile-based VR exposure therapy to address social anxiety and PTSD. Designing a highly detailed simulated grocery store, this VR program exposes participants to common triggers for social anxiety and PTSD symptoms (e.g., crowd, noise) as a part of clinical treatment. Results from this single case study show overall improvements in the participant's functioning, suggesting an important potential in how VR technologies might effectively produce simulated conditions necessary for exposure therapy.

While the use of simulation in social work has historically been known for teaching and learning purposes, there is a burgeoning body of literature in which simulation is used as a novel research methodology. Medical and healthcare researchers pioneered the use of simulation as a methodology in directly observing and examining practice behaviors and competencies among students and practitioners (Cheng et al., 2014). Similarly, social work researchers might also observe and examine clinicians' practice competencies within clinical sessions with trained actors portraying a realistic client scenario.

The third and final group of this Special Issue introduces five articles that can serve as a basis for advancing this methodological innovation in clinical social work research. In the first article, Asakura and colleagues report a scoping review of 24 social work studies, in which simulationbased data were used as an investigative methodology in conceptualizing, articulating or examining social work practice competencies. Taking some methodological limitations into account, the authors suggest that simulation and its proximity to actual practice with clients enable researchers to study clinical competencies related to working with vulnerable and marginalized populations without involving actual clients or their confidential health information. What follows in this group of the Special Issue is a series of articles that examines various clinical issues or competencies, using simulation-based research methods. As one of the social work pioneers in simulation-based research, Regehr and her colleague discuss research studies on clinical decision-making. They illustrate how high-fidelity simulations can be designed and provide concrete suggestions on how this type of research methodology might advance knowledge of social workers' complex clinical decisionmaking when faced with a high stakes matter. Tufford and colleagues similarly report a study about clinical decisionmaking around social workers' duty to report suspected child abuse and neglect, while navigating their therapeutic relationship with clients. Using OSCEs as simulation-based data, they explicate a range of clinical decision-making processes and strategies employed by social work students and experienced clinicians. Lee and colleagues report another simulation-based research study focused on child welfare practice. Using data from students' engagement with racially and culturally diverse professional actors trained to portray potential child abuse and neglect scenarios, the authors report social work students' conceptual understanding of and engagement with cross-cultural child welfare practice, highlighting how social workers draw from their own cultural lenses in making clinical decisions. Finally, this Special Issue concludes with Todd and colleagues' simulation-based study on navigating uncertainty in clinical practice. Directly observing and examining how social work students, recent social work graduates, and experienced clinicians interact with trained actors, the authors report the results from both video-recorded simulated clinical sessions and participants' post-session interviews. Authors of this article suggest that students and recent graduates might experience uncertainty as anxiety-provoking and a barrier for therapeutic progress. On the other hand, uncertainty might provide experienced clinicians an opportunity to further their understanding of the client's experiences and the development of therapeutic relationships, emphasizing navigation of uncertainty as an essential competency in clinical practice.

From case studies, theoretical articles, to research studies, this Special Issue features a range of contemporary work on simulation and clinical social work. These rigorous, diverse 
and cutting-edge contributions from Canada, the U.S. and Australia collectively demonstrate the significant contributions that simulation makes in advancing clinical social work and its commitment to competency-based education and practice. We hope that this Special Issue will stimulate an important and timely conversation about simulation and make a useful contribution for the readers.

\section{References}

Abrams, L. S., \& Dettlaff, A. J. (2020). Voices from the frontlines: Social workers confront the COVID-19 pandemic. Social Work. https://doi.org/10.1093/sw/swaa030.

Asakura, K., Lee, B., Occhiuto, K., \& Kourgiantakis, T. (2020a). Observational learning in simulation-based social work education: Comparison of interviewers and observers. Social Work Education. https://doi.org/10.1080/02615479.2020.1831467.

Asakura, K., \& Maurer, K. (2018). Attending to social justice in clinical social work: Supervision as a pedagogical space. Clinical Social Work Journal, 46(4), 289-297. https://doi.org/10. 1007/s10615-018-0667-4.

Asakura, K., Occhiuto, K., Todd, S., Leithead, C., \& Clapperton, R. (2020b). A call to action on Artificial Intelligence and social work education: Lessons learned from a simulation project using Natural Language Processing. Journal of Teaching in Social Work, 40(5), 501-518. https://doi.org/10.1080/08841 233.2020 .183234$.

Association of Social Work Boards. (2017). 2017 analysis of the practice of social work. Culpeper, VA: Author. Retrieved from https://www.aswb.org/wp-content/uploads/2017/04/2017-TechReport.pdf

Bandura, A. (1986). Social foundations of thought and action: A social cognitive theory. . Prentice-Hall.

Beddoe, L., Ackroyd, J., Chinnery, S. A., \& Appleton, C. (2011). Live supervision of students in field placement: More than just watching. Social Work Education, 30(5), 512-528.

Berliner, A. (1982). Enhancing social work education through the use of drama students as "clients" in role play. Arete, 7, 61-67.

Berzoff, J. (2011). Why we need a biopsychosocial perspective with vulnerable, oppressed, and at-risk clients. Smith College Studies in Social Work, 81, 132-166. https://doi.org/10.1080/00377 317.2011.590768.

Bogo, M., Rawlings, M., Katz, E., \& Logie, C. (2014). Using simulation in assessment and teaching: OSCE adapted for social work. . Council on Social Work Education.

Bogo, M., Regehr, C., Logie, C., Katz, E., Mylopoulos, M., \& Regehr, G. (2011). Adapting objective structured clinical examinations to assess social work students' performance and reflections. Journal of Social Work Education, 47(1), 5-18. https:// doi.org/10.5175/JSWE.2011.200900036.

Cheng, A., Auerbach, M., Hunt, E. A., Chang, T. P., Pusic, M., Nadkarni, V., \& Kessler, D. (2014). Designing and conducting simulation-based research. Pediatrics, 133(6), 1091-1101. https://doi.org/10.1542/peds.2013-3267.

Clubok, M. (1978). Evaluating the effectiveness of helping skills programs. Journal of Applied Social Sciences, 2, 33-41.

Galea, S., Merchant, R. M., \& Lurie, N. (2020). The mental health consequences of COVID-19 and physical distancing: the need for prevention and early intervention. JAMA Internal Medicine. https://doi.org/10.1001/jamainternmed.2020.1562.

Hardy, B. L., \& Logan, T. D. (2020). Racial economic inequality amid the COVID-19 crisis. Washington DC: Brookings.
Retrieved from https://www.hamiltonproject.org/assets/files/ EA_HardyLogan_LO_8.12.pdf

Haynes, S. (2021). 'This isn't just a problem for North America.' The Atlanta shooting highlights the painful reality of rising anti-Asian violence around the world. Time. Retrieved from: https://time.com/5947862/anti-asian-attacks-rising-worldwide/

Kolb, D. A. (1984). Experiential learning: Experience as the source of learning and development. . Prentice Hall.

Koprowska, J. (2003). The right kind of telling? Locating the teaching of interviewing skills within a systems framework. British Journal of Social Work, 33, 291-308.

Kourgiantakis, T., Bogo, M., \& Sewell, K. M. (2019). Practice Fridays: Using simulation to develop holistic competence. Journal of Social Work Education., 55(3), 551-564. https://doi.org/10.1080/ 10437797.2018.1548989.

Kourgiantakis, T., Sewell, K. M., Hu, R., Logan, J., \& Bogo, M. (2020). Simulation in social work education: A scoping review. Research on Social Work Practice, 30(4), 433-450. https://doi.org/10.1177/ 1049731519885015.

Larsen, J., \& Hepworth, D. H. (1982). Skill development of helping skills in undergraduate social work education: Model and evaluation". Journal of Education for Social Work, 18, 66-73.

Livsey, K., \& Lavender-Stott, E. (2015). Impact of vicarious learning through peer observation during simulation on student behavioural measures. Focus on Health Professional Education: A Multi-Disciplinary Journal, 16(4), 64-73.

Logie, C. H., Bogo, M., Regehr, C., \& Regehr, G. (2013). A critical appraisal of the use of standardized client simulations in social work education. Journal of Social Work Education, 49, 66-80. https://doi.org/10.1080/10437797.2013.755377.

Minuchin, S., \& Fishman, H. C. (1981). Family therapy techniques. . Harvard University Press.

Mitchell, B., Sarfati, D., \& Stewart, M. (2021). COVID-19 and beyond: A prototype for remote/virtual social work field placement. Clinical Social Work Journal. https://doi.org/10.1007/ s10615-021-00788-x.

Mole, L., Scarlett, V., Campbell, M., \& Themessl-Huber, M. (2006). Using a simulated chaotic home environment for preparing nursing and social work students for interdisciplinary care delivery in a Scottish context. Journal of Interprofessional Care, 20(5), 561-563.

Montalvo, B. (1973). Aspects of live supervision. Family Process, 12(4), 343-360.

National Association of Social Workers. (2017). Code of ethics. Washington, DC: Author. Retrieved from: https://www.socialworkers. org/About/Ethics/Code-of-Ethics/Code-of-Ethics-English

Parolin, Z. (2021). What the COVID-19 pandemic reveals about racial differences in child welfare and child well-being: An introduction to the Special Issue. Race and Social Problems, 13, 1-5. https:// doi.org/10.1007/s12552-021-09319-2.

Pfefferbaum, B., \& North, C. N. (2020). Mental health and the Covid19 pandemic. The New England Journal of Medicine, 383, 510 512. https://doi.org/10.1056/NEJMp2008017.

Petracchi, H. E. (1999). Using professionally trained actors in social work role-play simulations. Journal of Sociology and Social Welfare, 26, 61-69. Retrieved from https://scholarworks.wmich.edu/ jssw/vol26/iss $4 / 5$

Petracchi, H. E., \& Collins, K. S. (2006). Utilizing actors to simulate clients in social work student role plays: Does this approach have a place in social work education? Journal of Teaching in Social Work, 26, 223-233. https://doi.org/10.1300/J067v26n01_13.

Putney, J. M., Levine, A. A., Collin, C.-R., O'Brien, K. H. M., Mountain-Ray, S., \& Cadet, T. (2019). (2019) Teaching Note-Implementation of online client simulation to train and assess screening and brief intervention skills. Journal of Social Work Education, 55(1), 194-201. https://doi.org/10.1080/10437797.2018.1508394. 
Reinsmith-Jones, K., Kibbe, S., Crayton, T., \& Campbell, E. (2015). Use of Second Life in social work education: Virtual world experiences and their effect on students. Journal of Social Work Education, 51(1), 90-108. https://doi.org/10.1080/10437797.2015. 977167.

Robins, L., Brock, D. M., Gallagher, T., Kartin, D., Lindhorst, T., Odegard, P. S., et al. (2008). Piloting team simulations to assess interprofessional skills. Journal of Interprofessional Care, 22(3), $325-332$

Rousmaniere, T. (2017). Deliberate practice for psychotherapists: A guide to improving clinical effectiveness. Routledge.

Saltzburg, S., Greene, G. J., \& Drew, H. (2010). Using live supervision in field education: Preparing social work students for clinical practice. Families in Society, 91(3), 293-299. https://doi.org/10. 1606/1044-3894.4008.

Schenck, J., \& Cruickshank, J. (2015). Evolving Kolb: Experiential education in the age of neuroscience. Journal of Experiential Education, 38(1), 73-95. https://doi.org/10.1177/1053825914547153.

Schinke, S. P., Blythe, B. J., Gilchrist, L. D., \& Smith, T. E. (1980). Developing intake interviewing skills Social Work Research and Abstracts, 169(x), 29-34.

Schon, D. (1987). Educating the reflective practitioner. . Jossey-Bass.

Shulman, L. S. (2005). Signature pedagogies in the profession. Daedalus, 134(3), 52-59.
Sousa, D. (2017). How the brain learns (5th ed.). Thousand Oaks, CA.: Corwin.

Stegmann, K., Pilz, F., Siebeck, M., \& Fisher, F. (2012). Vicarious learning during simulations: Is it more effective than hands-on training? Medical Education, 46(10), 1001-1008. https://doi.org/ 10.1111/j.1365-2923.2012.04344.x.

Tai, D. B. G., Shah, A., Doubeni, C. A., Sia, I. G., \& Wieland, M. L. (2021). The disproportionate impact of COVID-19 on racial and ethnic minorities in the United States. Clinical Infectious Diseases, 72(4), 703-706. https://doi.org/10.1093/cid/ciaa815.

Taylor, K., \& Lamoreaux, A. (2008). Teaching with the brain in mind. New Directions for Adult and Continuing Education, 119, 49-59.

Washburn, M., \& Zhou, S. (2018). Teaching Note-Technologyenhanced clinical simulations: Tools for practicing clinical skills in online social work programs. Journal of Social Work Education, 54(3), 554-560. https://doi.org/10.1080/10437797.2017. 1404519.

Publisher's Note Springer Nature remains neutral with regard to jurisdictional claims in published maps and institutional affiliations. 